\title{
Utopías realizables: E.A. Vigo y el arte expandido en La Plata
}

\author{
María de los Ángeles De Rueda• \\ Universidad Nacional de La Plata
}

\begin{abstract}
Resumen
El trabajo recorre brevemente la poética de E.A. Vigo haciendo hincapié en el devenir creativo, desde sus primeras cosas hacia las utopías realizables y sus derivas en la formación de un arte expandido en la ciudad de La Plata. Sus propuestas artísticas parten del experimentalismo y llegan al arte de acción y más allá, en lo que podemos denominar la expansión del arte en el no arte. La figura del artista es revisada a lo largo de su trayectoria multifacética, en la que se pueden subrayar también los escritos para una teoría del (in) (no) arte a través del quehacer creativo. Finalmente se mencionan algunos grupos $\mathrm{y}$ artistas que acompańaron o siguieron sus propuestas.

\section{Palabras clave}

· arte expandido · señalamientos · experimentación · múltiples
\end{abstract}

\begin{abstract}
The work briefly through the poetics of E.A. Vigo emphasizing the creative evolution, from its first things towards the achievable utopias and its drifts in the formation of an art expanded in the city of La Plata. Their artistic proposals depart from the experimentalism and become action art and more, in what may be called the expansion of art not art. The figure of the artist is revised throughout his multifaceted career; where, also, it can be underlined the writings for a theory of the (in) (not) art through creative work. Finally, it is mentioned some groups and artists who have accompanied or followed their proposals.
\end{abstract}

\section{Key words}

- Expanded Art · Signs - Experimentation - Multiple

\footnotetext{
- Profesora y Licenciada en Historia de las Artes Plásticas por la Facultad de Bellas Artes de la UNLP/Magíster en Estética y Teoría de las Artes, FBA UNLP. Es Prof. Titular ordinaria Historia de las Artes VI y VII e Historia de las Artes Visuales III FBA, UNLP. Prof. Postgrado en la UNLP en la Maestría de Estética y Teoría de las Artes en la Facultad de Bellas Artes, Maestría Literaturas Comparadas en Humanidades y Ciencias de la Educación y en la Maestría de Conservación y Preservación del Patrimonio Arquitectónico en la Facultad de Arquitectura y Urbanismo. Es Docente-Investigadora categoría 1 Programa de incentivos UNLP-Ministerio de Educación de la Nación. Ha publicado numerosos artículos y compilado libros sobre arte, medios y cultura de redes, prácticas experimentales y artes en la ciudad de La Plata. Dicta cursos y conferencias sobre Artes Visuales en Argentina.
} 
1.

Para establecer un marco teórico de referencia de las propuestas artísticas, que parten del experimentalismo y llegan al arte de acción, conformando una tendencia conceptual extendida en América Latina a partir de 1960 y 1970, se considera a continuación el alcance del término arte conceptual con los nuevos comportamientos y la expansión de lo artístico, tal como lo señalaran Simón Marchan Fiz (1972) y Rosalin Krauss (1979) La figura de Edgardo Antonio Vigo es examinada a lo largo de toda su trayectoria, de la que se mencionan las ediciones de su Poesía experimental, la revista Diagonal Cero, la novísima poesía y Hexágono, los libros internacionales de estampillas, el museo de la xilografía, la comunicación a distancia, los objetos de bolsillo, las historietas herméticas, los señalamientos, desde el Manojo de Semáforos de la calles 1 y 60 en 1968 al señalamiento octavo de 1971 en Boca Cerrada en Punta Lara, que se convierte en una acción de memoria cada 21 de septiembre desde 1976, año en que desaparece su hijo Abel Palomo, víctima de la última dictadura militar. La síntesis del artista seguramente está contenida en las cajas de Biopsia, su archivo personal, curricular. Vigo fue un hacedor de lo múltiple, experimental y conceptual, a la vez. En el arte contemporáneo se puede distinguir una tendencia procesual resultante de las indagaciones que algunos movimientos o artistas en los años ' 60 realizaron sobre los aportes vanguardistas del dadaísmo (Duchamp y Schwitters) y el constructivismo. Estas matrices llevaron por acción diferida (Hal Foster, 2001) a la afirmación de procesos experimentales de ampliación del escenario artístico, en la redefinición de los materiales, las formas, el objeto, e incluso la relación artista-público, en el pasaje del arte al antiarte, el no arte o el (in) arte, como diría E.A.Vigo. De esta forma, la llamada expansión del arte a partir de los nuevos comportamientos artísticos se enlaza con el marco del estado conceptual ( Gerard Genette:1997) Los desplazamientos materiales e inmateriales de las formas del arte y los límites borrosos de las disciplinas, los usos diversos de lenguajes, el uso de tropos y figuras retóricas, los nuevos comportamientos, el uso del cuerpo como materia, del espacio, del territorio, la apertura de la obra a la coautoría del viejo espectador, construyen un proceso que tiene como resultado la experiencia artística contemporánea, expandida. Estas cuestiones que vuelven a pensarse en la actualidad están desarrolladas por la maquinaria creativa de Vigo.

La idea de un arte identificado con la vida del artista retorna una y otra vez desde el romanticismo hasta nuestros días, el arte es vida y la vida es arte según los practicantes del artecorreo, en un retorno. Como dice Mario Perniola (2016: 28) ya los situacionistas, por ejemplo, opusieron a la concepción sedentaria del artista, la experiencia de la deriva, entendida como conocimiento psíquico existencial del territorio, y pone como ejemplo a Carlos Ginsburg, uno de los jóvenes integrantes del Movimiento Diagonal Cero, que entre 1972 y 1982 viajó por el mundo, casi como un artista mendicante y su obra es un registro de lo diverso y circunstancial. En la obra de Vigo el territorio, lo local manifiesta su existencia y tiene una potencia política, la del circuito marginal. El esfuerzo por no encasillar sus producciones en una tendencia institucionalizada permite al artista trabajar en un marco de resistencia activa, es decir, elaborar desde lo local un diálogo crítico con sus contemporáneos fuera y dentro del arte. 


\section{2.}

Las primeras derivas tienen que ver con su formación. Las técnicas del grabado la permiten al artista E.A. Vigo incorporar los conceptos de múltiple y experimentación a la creación. El juego con los materiales extrartísticos, las lecturas sobre máquinas solteras imposibles y la revisión de los movimientos concreto y dadaísta lo acercan a las bases de sus objetos, máquinas y cosas, en el embrión del conceptualismo. Edgardo Antonio Vigo nace en la ciudad de La Plata en 1928 y fallece en 1997. En Francia establece contacto con un pintor riojano, Carlos Cáceres Sobrea, quien lo conecta con los artistas que, más tarde, son los representantes del movimiento cinético venezolano, especialmente Jesús Soto. En ese momento, el término vanguardia se relaciona con la experimentación y la investigación. En 1955 realiza su primera muestra individual en la Asociación Sarmiento de La Plata con Elena Comas, su esposa. Presenta Estructuras geométricas, donde comienza a trabajar en las denominadas Máquinas Inútiles. En 1957 aparecen los primeros objetos y cosas. Entre 1958 y 1960 edita, junto Miguel Ángel Guereńa y a Osvaldo Gigli, las revistas W.C. (cinco números dedicados al arte nuevo) y D.R.K.W.'60 (tres números que continúan en la misma línea de información). En 1962 edita la revista Diagonal Cero. De ésta se editan veintiocho números, hasta 1968, con excepción del número 25 que el artista lo dedica a la nada.

A partir de 1965, la revista Diagonal Cero sirve de espacio de intercambio con artistas brasileños, chilenos, uruguayos y europeos. Se destaca el intercambio de trabajos con Julien Blaine y Jean François Bory. A través de las conexiones con el grupo paulista, Vigo y sus compañeros se introducen en la poesía concreta, en los poemas procesos, en la poesía fónica y visual. Esta revista trimestral, dirigida y diagramada por Edgardo A. Vigo supera los 250 ejemplares de las primeras publicaciones y alcanza una tirada de 1000 , que el mismo autor vende o canjea tanto en Argentina como en América Latina y Europa. Diagonal Cero es una intención, una posibilidad, su primera utopía realizable. La cosa trimestral es un dispositivo gráfico de hojas sueltas con el que pueden jugar dentro de él sin orden premeditado. El propio autor la define como un medio o soporte de hojas sueltas, posiblemente intercambiables de acuerdo a las inquietudes del lector. Una edición con el carácter de múltiple generado tanto por su condición xilográfica como por la idea del objeto cinético orientada en la primera etapa a las novedades artísticas del medio regional y latinoamericano, que luego se convierte (a partir de los números 19 y 20) en un medio de difusión de experiencias en las que se borran los límites entre las artes.

En 1965, Vigo funda el Museo de la Xilografía y participa en la creación del Movimiento de Arte Nuevo en La Plata. El lema del movimiento es la renovación de la producción y la recepción de las artes en la ciudad, a partir de la renovación del campo. El Museo Provincial de Bellas Artes rompe con su línea presentando al MAN. El director del Museo, Ángel Osvaldo Nessi y Saúl Yurklevich reúnen un panorama nacional, mechado con algunas figuras locales, El Grupo Si, E.A.Vigo y los jóvenes del Movimiento Diagonal Cero, las tendencias más avanzadas del país. 
La ciudad de La Plata participa en esos años, especialmente a través de la labor de producción y difusión de algunos de los artistas e intelectuales, del debate sobre los nuevos destinos y mecanismos del arte.

En 1967, Edgardo Vigo integra el Primer Inventario Internacional de la Poesía Elemental, en la Galería Denise Davy, de París. En el mismo año se editan en esa ciudad sus Poemas Matemáticos Barrocos, en Contexte. En 1968, como ya subrayamos comienzan sus señalamientos, o acciones tanto públicas como privadas, en los que se incluye su famoso Manojo de semáforos en una esquina de la ciudad de La Plata, en cierto modo un ready made social.

En 1969, Vigo organiza en el Instituto Di Tella la Expo Internacional de Novísima Poesía '69, en la que se reúnen todas aquellas experiencias que tienen como antecedente la ejecución de artistas provenientes de la poesía visual o sonora. Esta muestra conforma una de las últimas actividades del Instituto, que completa el ciclo de experiencias visuales e intermediales del centro. La propuesta de Vigo, materializada en sus ediciones consistió en plantear un arte para y/o realizar, de alguna manera sus primeros esbozos de una teoría del no arte. Su planteo, en constelación con Duchamp (1957), Umberto Eco (1962) y Pierre Restany (1960), radica en la posibilidad de que el arte no está ya solo en la participación del buen observador sino en su activación constructiva, un arte a realizar, que altera las divisiones de los géneros heredados y que va a la meta de la integración total.

También en 1969, Vigo crea Un Arte a realizar, film Blanco sobre Blanco, Homenaje a Kasimir Malevich. Para hacer frente a las contradicciones del sistema artístico, Vigo plantea sus Proyectos a realizar como respuesta al caos estético: un aprovechamiento de la era tecnológica, pero con el uso libre de la misma por parte del armador (título que recibe el que corporiza el proyecto), quien asíllenaría su ocio, recibiendo un proyecto modificable en grado sumo que lo convierte en un recreador ilimitado, casi configurando un creador. El proyecto permite cambios, suplantaciones y agregados ya sea de materiales o de estructuras formales en aprovechamiento de lo lúdico. La colectivización no se haría bajo la técnica de lo múltiple, sino que estaría basada en la participación realmente activa (y no condicionada) del armador (De Rueda, 2003).

En 1969 también se realiza en la ciudad de La Plata la conferencia-suceso de Jorge Romero Brest sobre el Arte de consumo. El suceso consiste en una representación simultánea y en vivo de la estética de la época, vinculada a lo cotidiano, a la industria, a las cosas. Se pone el énfasis en el nacimiento de una nueva cultura y en las manifestaciones artísticas como forma de vida. Allí Vigo participa como artista invitado y comentarista del arte nuevo. Considera que el arte se coloca aquí en su máxima tensión: propone la desaparición de las formas, del objeto, de la trascendencia, lo cotidiano se bombardea desde el público. Una lección de vanguardismo concluía Vigo en un artículo titulado $N o-A r t e-S i{ }^{1}$, poniendo de relieve la importancia del acontecimiento producido. Por esos días en la ciudad de La Plata se produce el bautismo de un arte efímero, de acciones lúdicas en el contexto de las experiencias procesuales llevadas a cabo en el Instituto Di Tella. En el CAYC, Vigo organiza la muestra de Expo / Internacional de Proposiciones a Realizar-Investigaciones Poéticas. En este marco, aparece la Revista Experimental Hexágono, de trece números, y es a partir de 1972 que se acentúa el perfil político. Vigo presenta un artículo La calle, escenario del Arte Actual, en el marco de la intervención en Arte e ideología, CAyC al aire libre, realizada en la Plaza Roberto Arlt en setiembre de 1972. Al mismo 
tiempo organiza y participa con Horacio Zabala de la Comunicación a Distancia, que puede ser una obra colectiva en continua transformación. Vigo se acerca al mundo del artecorreo a partir de la práctica elaborada por Ray Jonson en 1950 con la Escuela de Correspondencia de Nueva York. En 1975 organiza con Zabala la última exposición internacional de Arte correo '75 en la galería Arte Nuevo de Buenos Aires. Usaba postales, matasellos, sobres impresos de madera no convencionales.

Asimismo, sigue con sus proyectos de señalamientos, sus acciones individuales definidas como récord de vida y sus objetos, que en cierta medida son el corolario de su producción. Estas producciones forman parte de sus Prospectivas del pasado. Sus acciones en la calle y en espacios privados se multiplican, durante los ' $80 \mathrm{y}$ hasta su muerte ocurrida en 1997 . Sus anteproyectos de proyectos a realizar interpelan a la violencia y desesperanza poniendo énfasis en la condición existencial y en la violencia simbólica de la poesía elemental. Su trabajo se sintetiza en la comunicación a distancia y las Estampillas que establecen lazos solidarios contra la violación de los derechos humanos y los abusos de poder.

\section{Acuse de recibo / La figura fusionada del artista}

Entre 1977 y 1983 se concreta la fusión artística G.E.MarxVigo (Graciela Gutiérrez Marx y Edgardo Antonio Vigo) realizando por varios ańos (entre la dictadura y la democracia) una multiplicidad de materialidades y acciones en «correspondencia». El 22 de agosto de 1977 (una fecha clave en su producción, ya que rememora la masacre de Trelew) Vigo le propone trabajar en dupla, con una firma en común.

En Acuse de recibo (1979), proponen una fllatelia marginal creativa y paralela:

Se trata de juntar y hacer sin principio ni fin (...) No es coleccionismo, sino rejunte libre que encuentra su justificación en el hecho mismo de la creatividad puesta en acción ${ }^{2}$.

Como recuerda Graciela Gutiérrez Marx:

Y el network del ARTECORREO abrió canales, llenó sus arcas de tesoros, diálogos a distancia donde convalidar la red espiritual de comunicación, de resistencia descentralizada y hermandad intercontinental. La casilla alimentó el vacío y la muerte, con voces planetarias. La fuerza del colectivo nos ofreció el terreno para una batalla interminable contra el capitalismo y el virus del control. Llegó a Buenos Aires Ulises Carrión y Julien Blaine nos visitó en La Plata. Así comenzó una otra-misma vida, la de G.E. Marx-Vigo, como producto del compromiso ideológico, que sólo podía manifestarse en la auto marginación. (De Rueda, 2007)

En 1983 G.E. MarxVigo presenta en el Complejo Cultural Museo de Telecomunicaciones en la costanera sur, en Buenos Aires, su Anteproyecto de fusión para una contestación abierta y transitoria propuesta hacia el año 2000. La acción continuaba el trabajo de dicha fusión y a la vez lo cerraba como acción-cita de los dos en cada primavera en Boca cerrada, Punta Lara. Es una de las últimas producciones de la fusión artística, una experiencia de arte colaborativo, síntesis de las citas de los dos artistas, que cada primavera las practicaban en Boca Cerrada, Punta Lara, para devolver-se y 
devolver la esperanza en el florecimiento, arrebatada por el horror del Terrorismo de Estado. Arman un catálogo que registra la acción del 21 de septiembre de 1982: en esa ocasión echan a volar una banderola, una carta con dos globos. Lo que señalaban cada año «era el silencio de las primaveras que no brotan (...) siempre quisimos rescatar la vida, como si en estos rituales íntimos pudiéramos resguardar la vida».

En el catálogo de la muestra resumía Horacio Safonz:

El Anteproyecto de fusión para una contestación abierta y transitoria propuesta hacia el año 2000 de Marx-Vigo, es un fresco ejemplo de obra abierta. No sólo porque su construcción puede remontarse al infinito; es que este anteproyecto (adviértase el término que indica cuán modificable es desde el inicio), está enmarcado en la corriente que representan Marx-Vigo, el Mail Art, cuya base es la comunicación postal. Las eventuales respuestas a los envíos que Marx-Vigo realicen, integrarán y, lógicamente, modificarán el cuerpo físico del anteproyecto. La red del sistema instituido (correo), además de canales de alimentación de la obra, se convierten en extensión ${ }^{3}$.

Con el advenimiento de la democracia la fusión de identidades con Vigo se disuelve. Aunque continúan con sus proyectos colectivos. Ese año Vigo participa junto a Graciela Gutiérrez Marx, Susana Lombardo, Claudia del Río, Jorge Orta, Noni Argañaraz, Mamablanca, Hilda Paz, Claudia Orta, Graciela Sacco y Carlos Pamparana de la organización propuesta por el uruguayo Clemente Padín de la Asociación Latinoamericana y del Caribe de Arte Correo.

Se puede pensar que estas prácticas son residuales de los circuitos experimentales y marginales que el mismo Vigo desarrolló, de la expansión del arte al no arte entre los años ' 60 , '70 y ' 80 inclusive, vivificados en nuestra contemporaneidad. Por eso podemos pensar en una manifestación incipiente de arte colaborativo como colectivo: un modo de hacer conjunto, co-autoral, abierto y marginal en una red de intercomunicación vía postal, no hegemónico, propuestas alternativas a la institución arte.

Vigo fue un creador multifacético, y desde la periferia del sistema dinamizó los procesos de artificación (Heinich, Schapiro, 2012), recorriendo el sinuoso camino del arte si-no arte como utopías realizables en la expansión de los procesos artísticos en los modos de pensar y de vivir.

\section{Notas}

${ }^{1}$ Escribe Vigo en la revista Ritmo, № 5, La Plata, 25 de agosto de 1969, representa la avanzada artística, y sienta las bases de su teoría de arte si-no arte otro, irradiando en los jóvenes artistas el concepto del arte como un acto de libertad, en Luis Pazos y sus experiencias de poesía fónica, otros como Rayo Puppo pintura corporal, y sucesos.

${ }^{2}$ Un tarjetón en el cual se explayaron acerca del arte postal, el circuito marginal de la filatelia y la capacidad creadora en acción, http://www. merzmail.net/acuse.htm

${ }^{3}$ El Profesor Horacio Safons fue Director del Complejo Cultural Museo de Telecomunicaciones y Secretario General de la Asociación Argentina de Críticos de Arte en ese momento. Archivo Caja Biopsia 1983/84 


\section{Referencias bibliográficas}

\section{Libros}

De Rueda, M. (2003). Utopías en la calle. En Arte y Utopia la ciudad desde las artes (Pp. 93-105). Buenos Aires: La Marca, Asunto Impreso ediciones

Eco, U. (1962). Obra Abierta. Barcelona: Planeta-De Agostini. (1992) Foster, H. (2001). El retorno de lo real, la vanguardia a finales del siglo. Madrid: Akal.

Genette, G. (1997). La obra del Arte. Barcelona: Lumen

Krauss, R. (1979). La escultura en el campo expandido en Foster, H. La posmodernidad. Barcelona: Kairos. (1985)

Marchan Fiz, S. (1972). Del Arte objetual al arte del concepto. Madrid: Alberto Corazón.

Perniola, M. (2016). El Arte expandido. Madrid: Casimiro.

Restany, P. (1981). La otra cara del Arte. Buenos Aires: Rosemberg Rita.

\section{Revistas}

De Rueda, M, (2007). El Arte Platense en los Primeros Años 80: Entre La Guerra De Malvinas, Los Desaparecidos y La Esperanza Democrática. BOA Boletín Instituto de Historia del Arte Argentino y Americano, FBA UNLP.

Heinich, N. y Shapiro, R. (EHESS) (2012). ¿¿Cuándo hay artificación?. Revista Digital Contemporary Aesthtics (4)

\section{Fuentes electrónicas}

VIGo, E.A. Un arte a realizar, 1968-69, Archivo Merz Mail. Recuperado de http://www.merzmail.net/ea.htm

GEMARXVIGO, Acuse de recibo 1979, Archivo Merz Mail. Recuperado de http://www.merzmail.net/ea.htm

VIGo, E.A. Del que hacer creativo, 1984, en Archivo en Centro de Arte experimental. Recuperado de http://www.caev.com.ar/

Revista Buzón de Arte/Arte de Buzón. Año1, No 2. mayo 1976.

Caracas, Venezuela. Calle Páez. Edificio Robertico Ap. 31, Chacao, Caracas Venezuela. Recuperado de https://icaadocs.mfah.org/icaadocs/ ELARCHIVO/RegistroCompleto/tabid/99/doc/1102031/language/ es-MX/Default.aspx

\section{De Rueda, María de los Ángeles}

